\title{
Embrittled Ancient Silver and Iron Objects and Their Conservation
}

\section{Russell Wanhill}

National Aerospace Laboratory NLR, Amsterdam, the Netherlands, P.O. Box 90502, 1006 BM Amsterdam

wanhill@nlr.nl

\section{Introduction}

Embrittlement of ancient metals is often complex. The details of embrittlement should be investigated in order to select the best remedial measures for restoration and conservation. This article surveys the techniques used for investigating several ancient embrittled silver artifacts and an iron pile-shoe from a Roman bridge. The possibilities for preserving such objects are also discussed.

\section{Silver Embrittlement}

The investigated artifacts were an Egyptian vase, the Gundestrup Cauldron, and a Byzantine paten (a plate used during celebration of the Eucharist). Table 1 lists the techniques and their purposes: SEM = Scanning Electron Microscope; SE, BSE $=$ Secondary and BackScattered Electron imaging; EBSD = Electron BackScatter Diffraction; EDX = Energy Dispersive analysis of X-rays. The choice of techniques depended on the accessibility and condition of samples from the artifacts. For example, the vase samples were initially unembedded fragments that could be examined fractographically. The other samples had already been prepared for metallography.

There are three types of embrittlement likely in these objects: corrosion-induced, microstructurally induced, and synergistic.

Corrosion-induced embrittlement is due to several forms of selective corrosion. Intergranular corrosion is the most commonly reported. This can occur in mechanically worked and annealed objects, which constitute the majority. Interdendritic corrosion can occur in castings, which are uncommon, especially in the Old World. Corrosion along slip lines and deformation twin boundaries can occur in objects that have not been annealed after (final) mechanical working, which includes striking a coin and decorating by chasing and

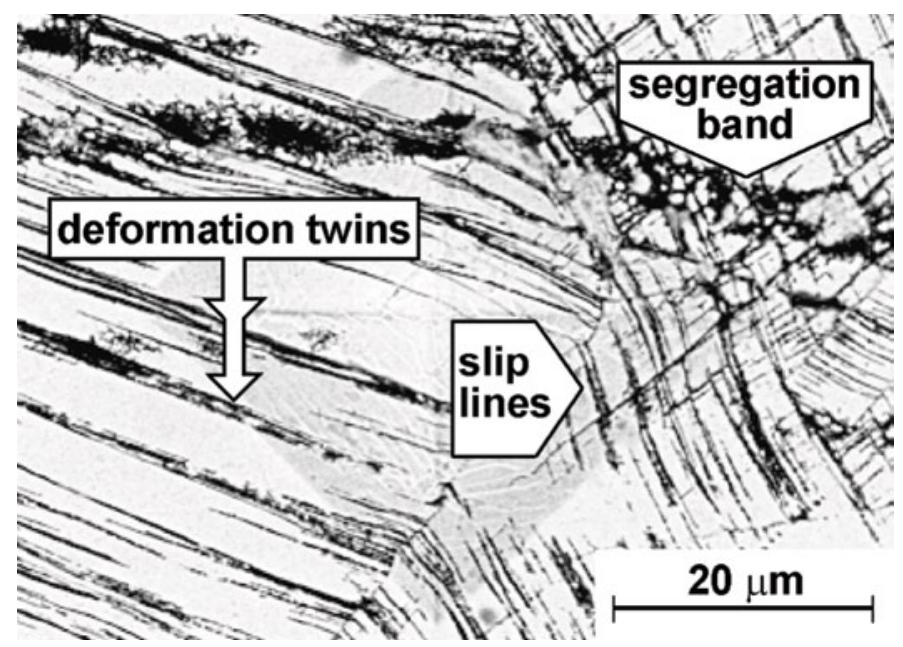

Figure 1: Corrosion-induced embrittlement along deformation twins, slip lines, and copper-rich segregation bands in the Egyptian vase [1].

stamping. Inside the metal these kinds of corrosion can lead to additional corrosion along segregation bands. These bands are the remains, modified by working and annealing, of solute element segregation (coring) and interdendritic segregation that occurred during solidification of an ingot or cupelled button.

Microstructurally induced embrittlement is characterized by brittle intergranular fracture, with sharply defined cracks and grain boundary facets. The embrittlement is most probably a consequence of long-term low-temperature aging, whereby an impurity element, or elements, segregates to grain boundaries. The available evidence indicates lead to be the most likely perpetrator $[2,3]$, though this has yet to be verified directly. Other impurity elements might be involved, notably bismuth [3].

Table 1: Diagnostic techniques for ancient silver embrittlement [1].

\begin{tabular}{|c|c|c|c|c|}
\hline Purposes & Techniques & $\begin{array}{c}\text { Egyptian } \\
\text { Vase }\end{array}$ & $\begin{array}{l}\text { Gudestrup } \\
\text { Cauldron }\end{array}$ & $\begin{array}{c}\text { Byzantine } \\
\text { Paten }\end{array}$ \\
\hline \multirow{2}{*}{$\begin{array}{l}\text { Determine basic } \\
\text { condition and "hidden" } \\
\text { damage }\end{array}$} & Visual inspection & $\bullet$ & & $\bullet$ \\
\hline & $\mathrm{X}$-ray radiography & $\bullet$ & & \\
\hline \multirow{6}{*}{$\begin{array}{l}\text { Final manufactured } \\
\text { condition; grain size; } \\
\text { chemical composition; } \\
\text { internal damage and } \\
\text { cracking; types of } \\
\text { embrittlement }\end{array}$} & Light optical metallography & & & \\
\hline & SEM metallography and analysis & & & \\
\hline & -SE andf BSE images & $\bullet$ & & $\bullet$ \\
\hline & -EBSD & & $\bullet$ & \\
\hline & - EDX & $\bullet$ & & $\bullet$ \\
\hline & Microhardness & $\bullet$ & & \\
\hline Types of embrittlement & SEM fractography & $\bullet$ & & \\
\hline
\end{tabular}




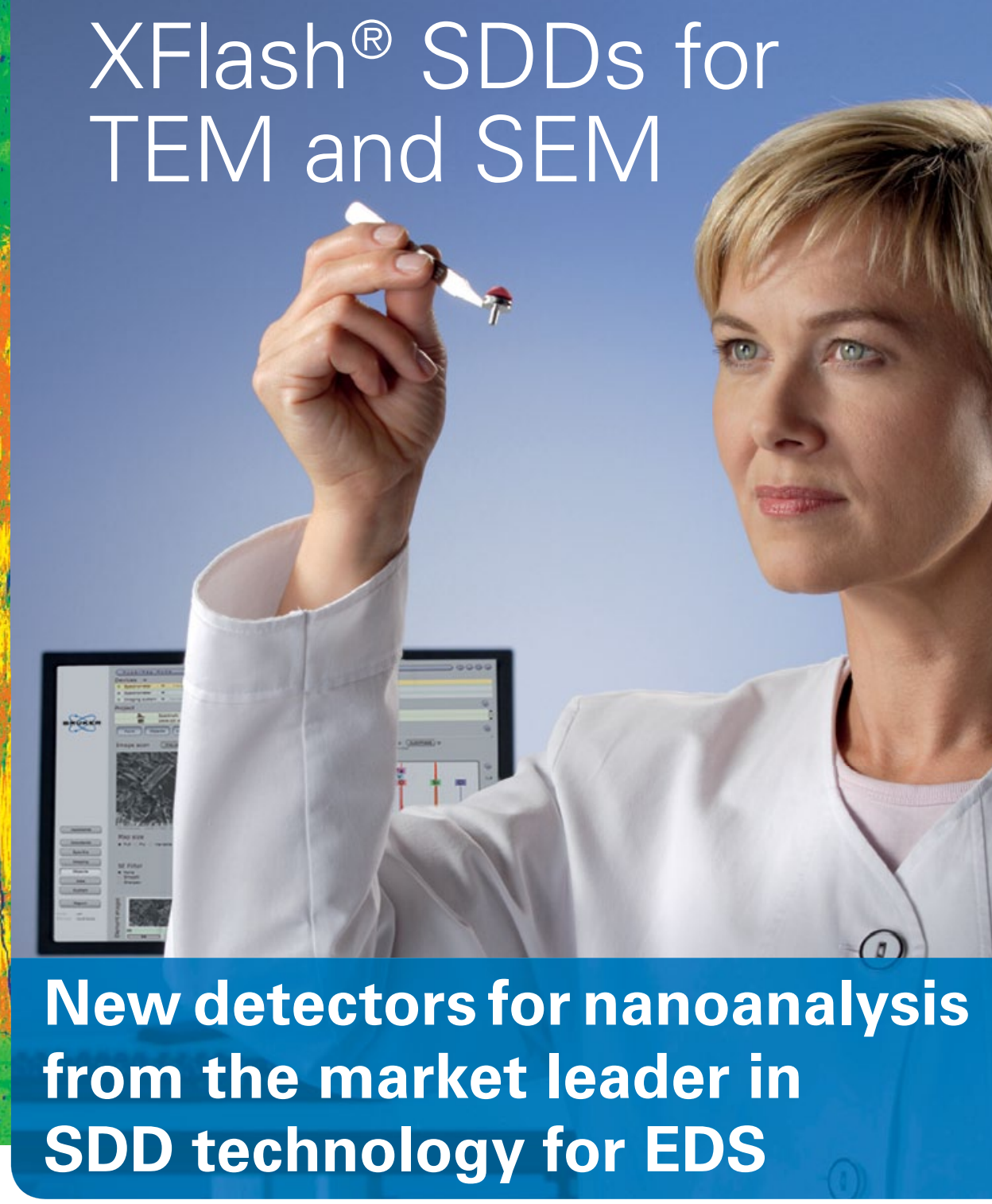

The XFlash ${ }^{\circledR}$ Silicon Drift Detectors are part of our QUANTAX EDS systems

- Unmatched resolution at all energies (Mn K $\alpha \leq 123 \mathrm{eV}, \mathrm{C} \mathrm{K} \alpha \leq 46 \mathrm{eV}, \mathrm{F} \mathrm{K} \alpha \leq 54 \mathrm{eV}$ )

$>$ superb line separation at low energies

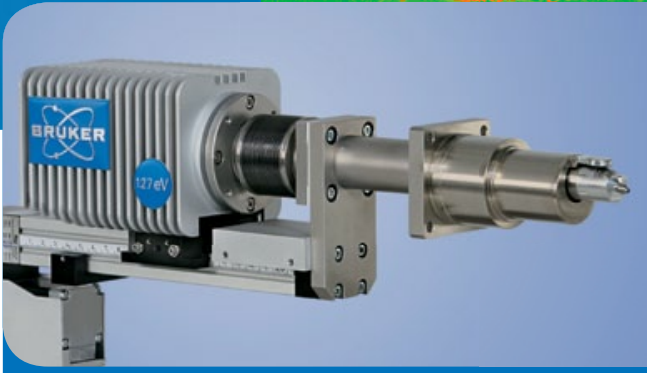

XFlash $^{\circledR} 5030$ T for TEM

- 250 new L, M, N lines below 4 keV in Bruker's unique atomic database > excellent low energy element ID > reliable low energy quantification results 


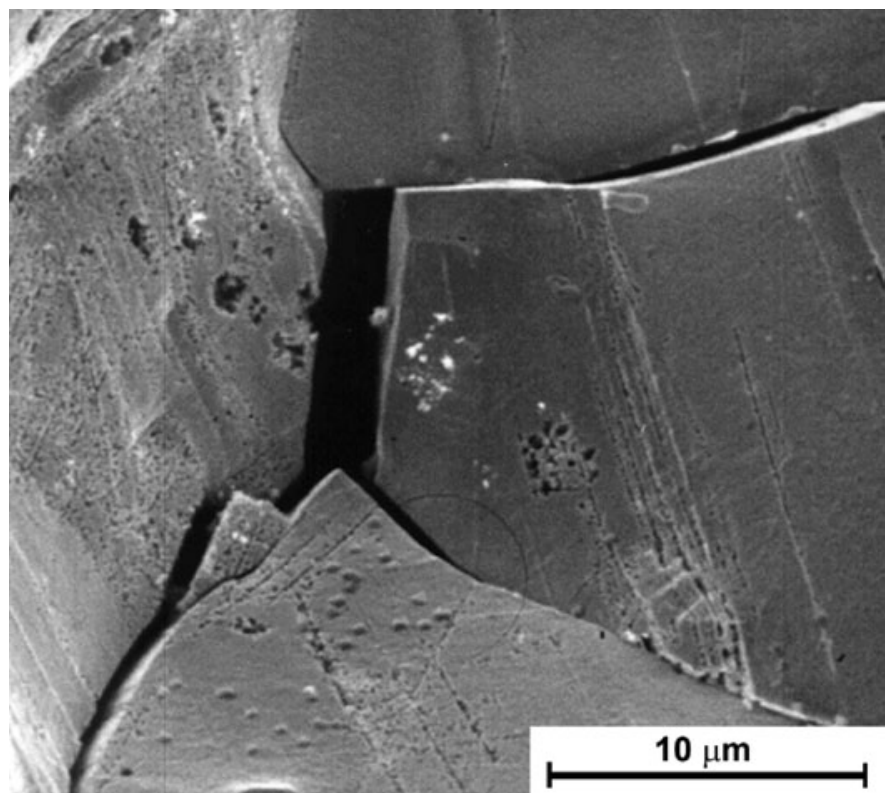

Figure 2: Microstructurally induced brittle intergranular fracture in the Egyptian vase [2].

Synergistic embrittlement combines corrosion-induced and microstructurally induced embrittlement. For example, corrosion along slip lines, deformation twin boundaries, and segregation bands can result in cracks. These cracks can then initiate fracture along microstructurally embrittled grain boundaries-which may fracture anyway, though less easily-under the action of external loads. In turn, the grain boundary fractures expose more slip lines, deformation twins, and segregation bands to the environment and increase the opportunities for corrosion.

SEM metallographic and fractographic examples of all three types of embrittlement are given in Figures 1-3. Retained cold-work is generally responsible for corrosion-induced embrittlement. This can be seen from the EBSD Inverse Pole figure (IPF) color-coded maps in Figure 4, which show annealed and cold-worked samples from the Gundestrup Cauldron. The annealed sample is uncorroded even though there is extensive discontinuous precipitation of copper along the grain boundaries. This is notable because the eminent metallurgist Cyril Stanley Smith took the view that grain boundaries along which discontinuous precipitation had occurred seemed to be highly susceptible to corrosion [4]. Also, limited evidence for the Byzantine paten $[2,3]$ suggested that corrosion occurred along grain boundaries with discontinuous precipitation. On the other hand, the Gundestrup Cauldron results are consistent with the experience of Peter Northover [5] who observed intergranular corrosion and cracking in ancient Bactrian silver despite copper contents less than 1 percent, which is almost certainly too low for discontinuous precipitation to occur [6].

\section{Iron Embrittlement}

A recent brittle fracture in a Roman pile-shoe recovered from the Maas riverbed in 1992 was investigated in collaboration with three other institutes in the Netherlands. See Table 2.

Figure 5 shows a detail of the fracture, which was caused by the pile-shoe falling onto a concrete floor during storage. This obviously intergranular fracture was attributed to local decarburisation during manufacture (a local carbon content of only $33 \mathrm{ppm}$ ) and subsequent embrittlement by high-temperature phosphorus segregation to the ferrite grain boundaries. The decarburisation would have occurred owing to locally oxidizing conditions in the smithing hearth, and the virtual absence of carbon would then permit phosphorus segregation to the ferrite grain boundaries [7]. It was also found that the pile-shoe was covered by a surface corrosion layer of akaganeite (an iron oxide) which would have formed after the pile-shoe was recovered [8].

\section{Remedial measures for restoration and conservation}

Modern restorations and conservation are concerned with both technical and ethical aspects. Essentially, this means respecting an object's integrity and using reversible remedial measures. However, reversibility is a controversial topic and not always practicable.

Remedial measures for silver. Table 3 summarizes how the basic condition and type of embrittlement of ancient silver

Table 2: Diagnostic techniques for embrittlement of an iron pile-shoe [1, 7].

\begin{tabular}{|l|l|c|}
\hline Techniques & Specific Aspects & Organization \\
\hline Macrofractography & $\begin{array}{l}\text { Brittle fracture, corrosion } \\
\text { Intergranular + cleavage fracture }\end{array}$ & Het Valkhof \\
SEM/FEG-SEM fractography & Microstructure, hardness & CORUS, NLR \\
\hline Optical metallography & & \\
\hline Chemical analysis & & PR-MA \\
Bulk & Iron and surface corrosion layer & CORUS \\
X-Ray Diffraction (XRD) & CORUS \\
X-Ray Fluorescence (XRF) spectroscopy & Iron composition & \\
Combustion + InfraRed (IR) detection & Carbon and sulphur content of iron & CORUS/PR-MA \\
Metallographic surfaces & Iron and inclusion compositions & \\
SEM+EDX, Electron Probe MicroAnalysis & Phosphorus and oxygen line scans & PR-MA \\
(EPMA)+WDX & & \\
Fracture surfaces & Grain boundary segregation & R-ray Photoelectron Spectroscopy (XPS)
\end{tabular}

Het Valkhof = Museum Het Valkhof, Nijmegen; PR-MA = Philips Research-Materials Analysis, Eindhoven; CORUS = Corus Research, Development and Technology, Umuiden 
Table 3: Potential remedial measures for restoration and conservation of ancient silver [2, 3].

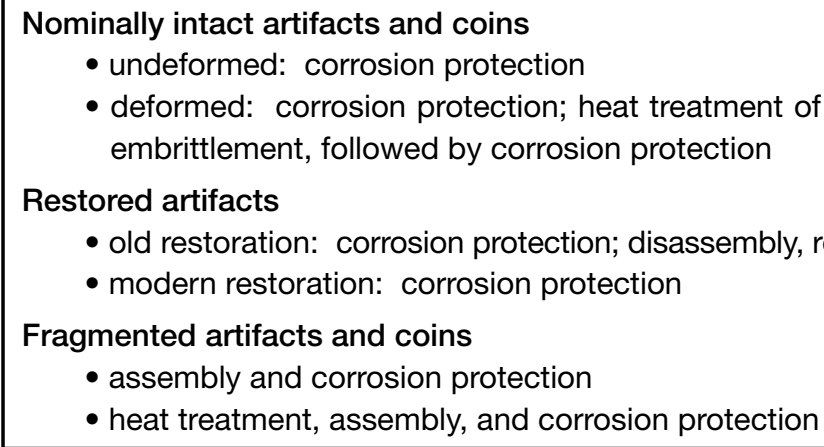
embrittlement, followed by corrosion protection

\section{Restored artifacts}

- modern restoration: corrosion protection

\section{Fragmented artifacts and coins}

- assembly and corrosion protection

- heat treatment, assembly, and corrosion protection

- deformed: corrosion protection; heat treatment of coins to remove microstructural

- old restoration: corrosion protection; disassembly, reassembly, corrosion protection method for corrosion-embrittled artifacts is warranted.

Remedial measures for iron pile-shoes. Many more pile-shoes were recovered besides the accidentally fractured one. Investigation of this pile-shoe indicated two aspects for conserving the others. Firstly, these must be expected to have surface corrosion layers containing akaganeite. Because akaganeite is hygroscopic, point to potentially appropriate remedies. Corrosion protection can be a generally applicable measure, but heat treatments are not. Heat treatments obviously are irreversible and should be allowed only if preceded by thorough diagnostic investigations and if judged essential by expert technical staff.

The most likely and feasible corrosion protection measure is cleaning, outgassing to dry crack surfaces and any entrapped corrosion products, and application of a protective coating. The choice of cleaning methods and protective coatings requires much forethought and care [3,9]. An innovative cleaning method is hydrogen plasma reduction. This requires no more than an hour at temperatures of $40-100^{\circ} \mathrm{C}$, which minimizes or avoids significant alterations of an artifact's microstructure, especially at the lower end of the temperature range. The hydrogen plasma reduces surface corrosion products to metallic silver and offers a possible alternative to heat treatment of artifacts that are penetrated and severely embrittled by corrosion. Such heat treatments require temperatures of $700^{\circ} \mathrm{C}$, or more, to remove the corrosion and are generally unacceptable because of a high risk of damaging the artifacts. Hence further investigation of the hydrogen plasma reduction corrosion will continue unless actively prevented by drying out the corrosion layers and either storing the pile-shoes in a low-humidity environment [8] or applying a protective (organic) coating. Secondly, some of these pile-shoes could also have local carbon contents that are extremely low. Thus if any are to be removed from storage, and whether or not they are still attached to piles, they should be handled and transported with care to avoid breakages. MT

\section{References}

[1] RJH Wanhill, "Embrittlement of archaeological silver and iron, National Aerospace Laboratory Report NLR-TP2009-105," Amsterdam, the Netherlands: to be published in Structural Integrity and Life 9 (2009).

[2] RJH Wanhill, Journal of Failure Analysis and Prevention 5 (2005) 41-54.

[3] RJH Wanhill, A Lecture Course on Metallurgy, Embrittlement and Conservation of Ancient Silver, National Aerospace Laboratory NLR, Amsterdam, the Netherlands, 2008.

[4] CS Smith, Application of Science in Examination of Works of Art, WJ Young, ed., Boston Museum of Fine Arts, Boston, 1965, 20-52.

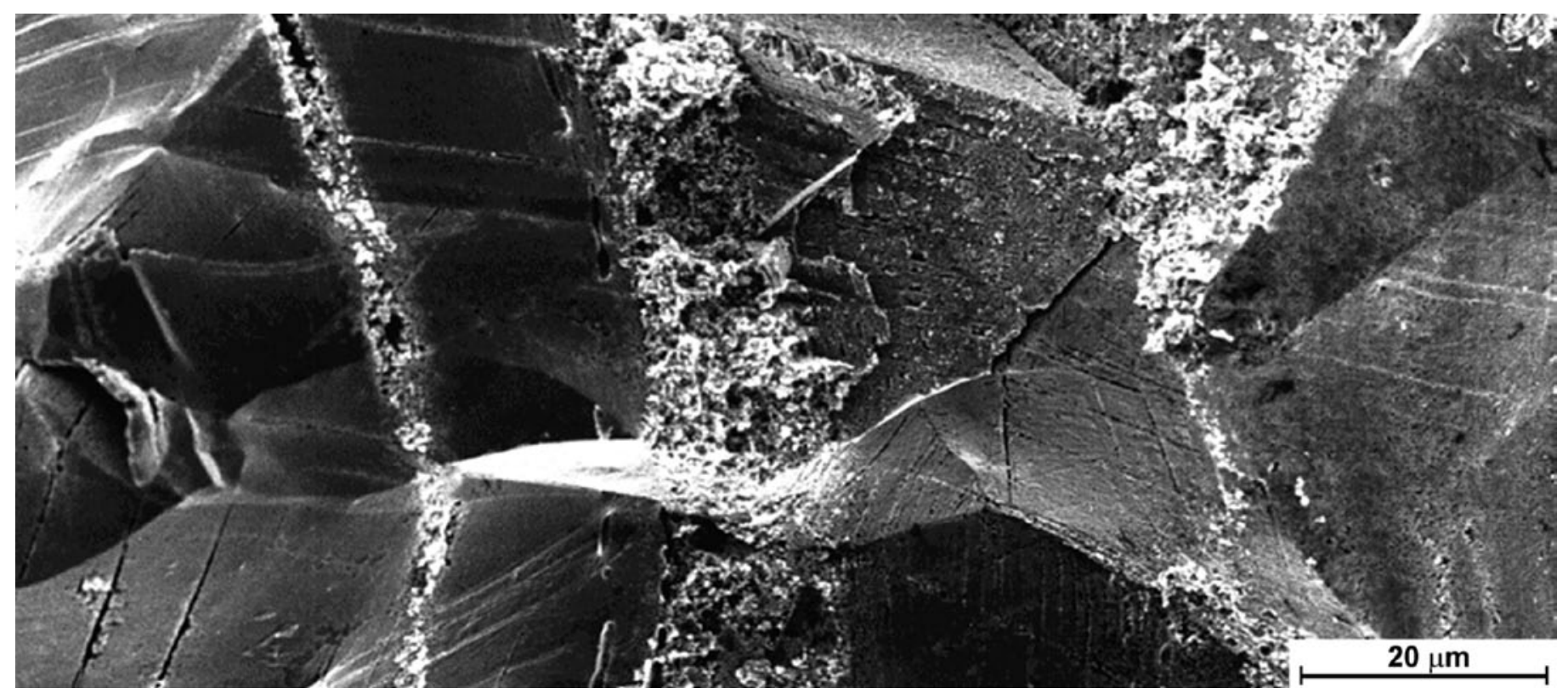

Figure 3: Synergistic embrittlement example: Microstructurally induced intergranular fracture and corrosion-induced damage and cracking along segregation bands in the Egyptian vase [1]. 

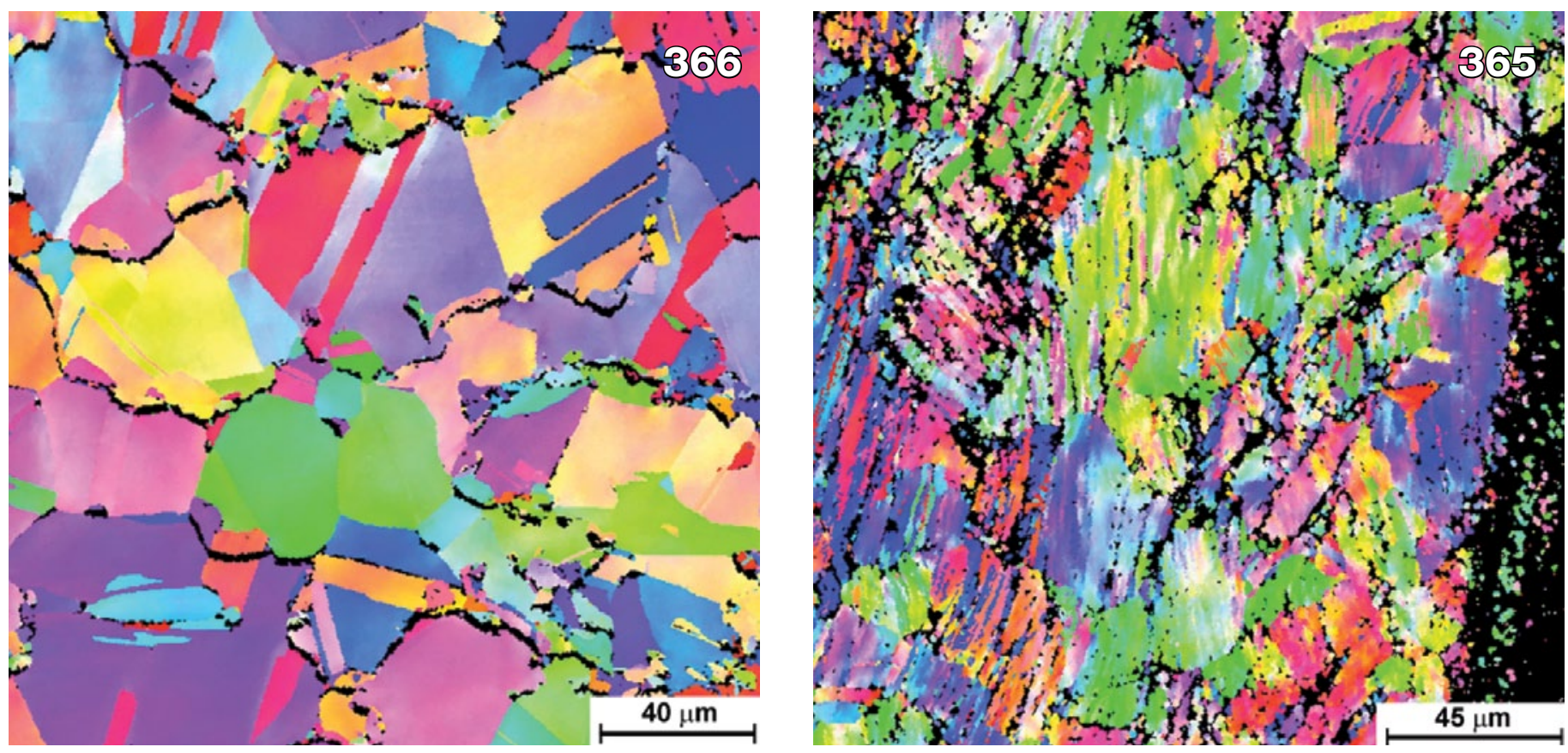

Figure 4: EBSD IPF color-coded maps for Gundestrup Cauldron sample 366 (annealed) and sample 365 (cold-worked). The sample 366 image shows extensive discontinuous precipitation of copper along the grain boundaries. Black regions in the sample 365 image are due to corrosion damage and cracking [1].

[5] JP Northover, Personal communication, Department of Materials, Oxford University, 1999.

[6] RJH Wanhill, Archaeological Silver Embrittlement: a Metallurgical Inquiry, NLR-TP-2002-224, National Aerospace Laboratory NLR, Amsterdam, the Netherlands, 2002.

[7] RJH Wanhill, PA Seinen, RA Rijkenberg, HJM Meijers, Historical Metallurgy 41 Part 1 (2007) 32-39.

[8] L Selwyn, Metals and Corrosion: A Handbook for the Conservation Professional, Canadian Conservation Institute, Ottawa, Canada, 2004.

[9] J van Reekum, E Moll, Coating silverware: from daily use to museum object, Zeven Ijzersterke Verhalen over Metalen, ed.

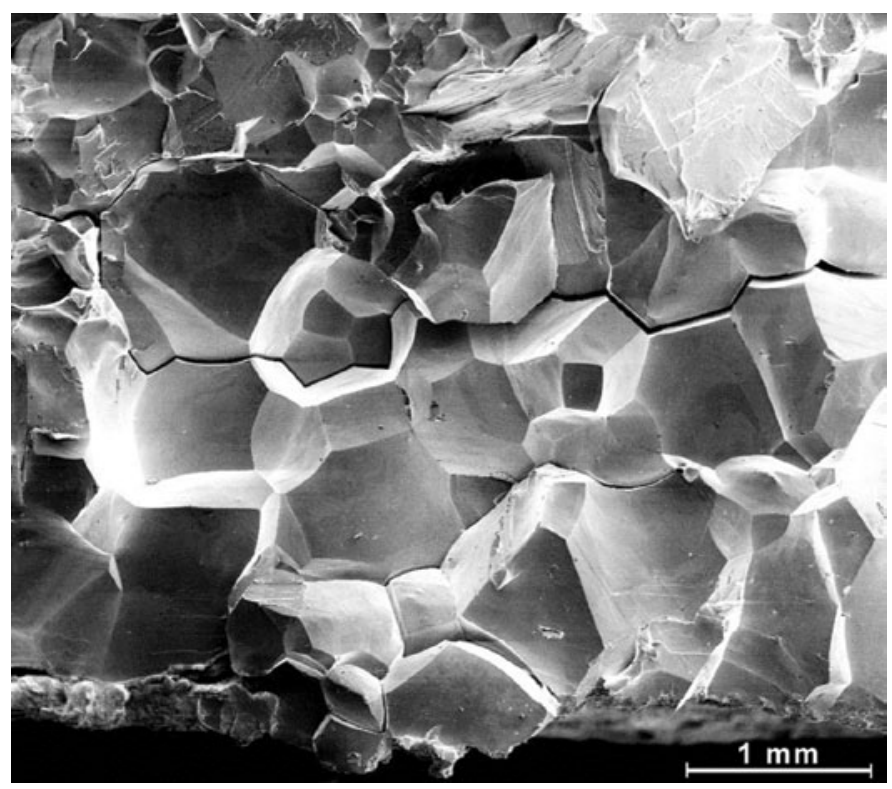

Figure 5: Brittle intergranular fracture of an iron pile-shoe from a Roman bridge [1].
HA Ankersmit and JA Mosk, Netherlands Institute for Cultural Heritage, Amsterdam, the Netherlands, 2000, 74-79.

\section{Why have over 2,000 scientists in 35 countries selected Minus $\mathbf{K}^{\circledR}$ vibration isolators?}

\section{Our Negative Stiffiness systems deliver 10x to $100 x$ better} performance than air systems and even better than active systems.

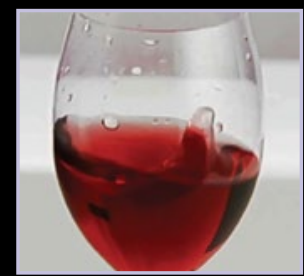

Without Minus $\mathrm{K}^{\circledR}$

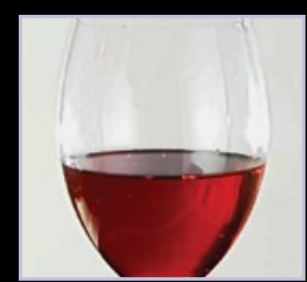

With Minus $\mathrm{K}^{\circledR}$
The best performance and the lowest price. That's hard to beat!

VIBRATION ISOLATION BY:

Mminus k'TECHNOLOGY

460 S. Hindry Ave., Unit C, Inglewood, CA 90301

Tel: 310-348-9656 Fax: 310-348-9638

sales@minusk.com • www.minusk.com 
SII $0^{\circ}$

SII NanoTechnology USA Inc.

\section{Silicon Drift Detector}

NO LN2 • Active area $40 \mathrm{~mm}^{2} \bullet<130 \mathrm{eV}$ FWHM at $5.9 \mathrm{keV} \bullet$ ICR $1.5 \mathrm{Mcps} \bullet$ OCR up to $350 \mathrm{kcps}$

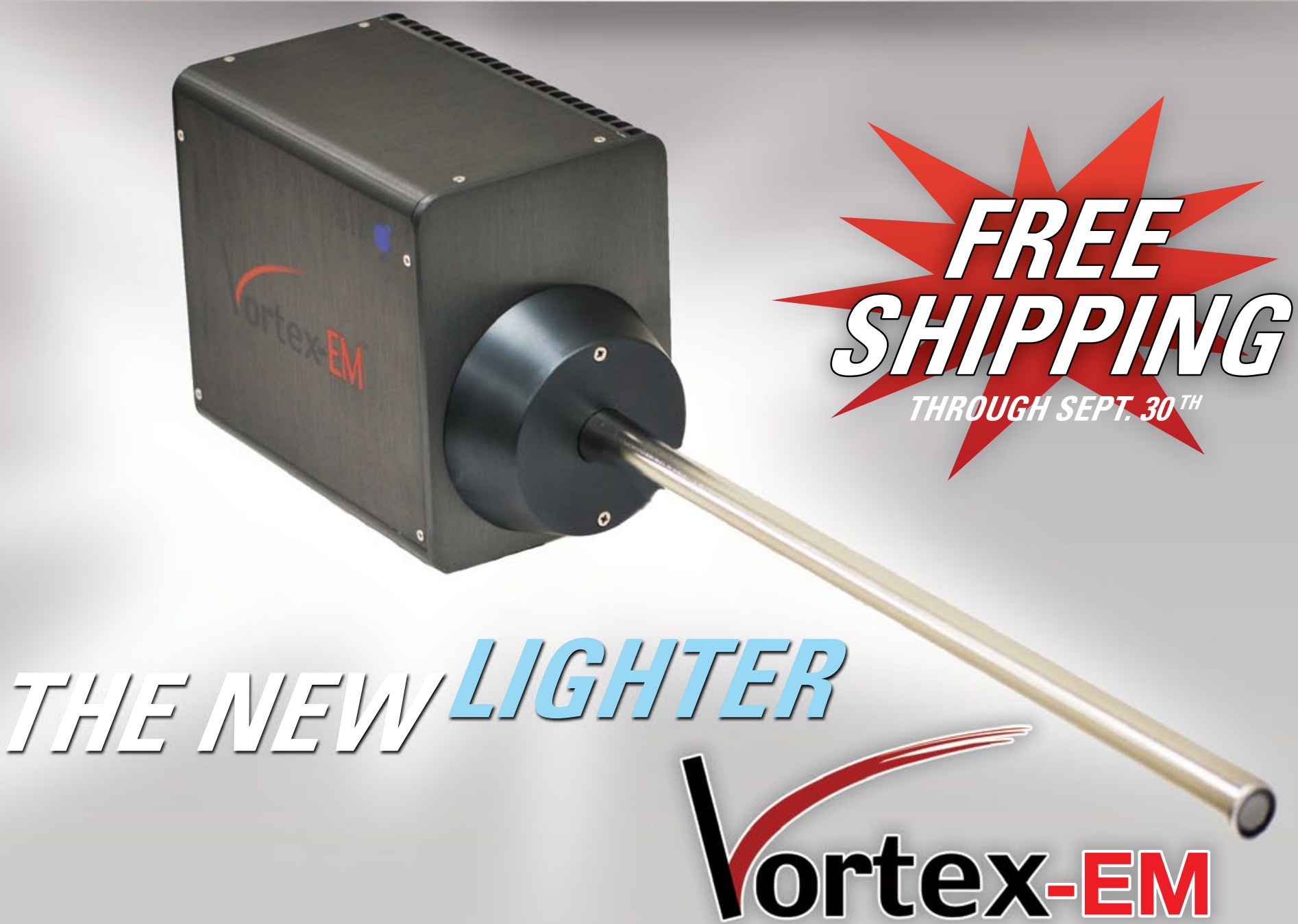

\section{BREAKTHROUGH PERFORMANCE}

$\mathrm{C}$ and the B peaks are completely separated from noise by the Vortex-EM detector. It therefore, facilitates light element detection while performing microanalysis and fast elemental mapping applications.

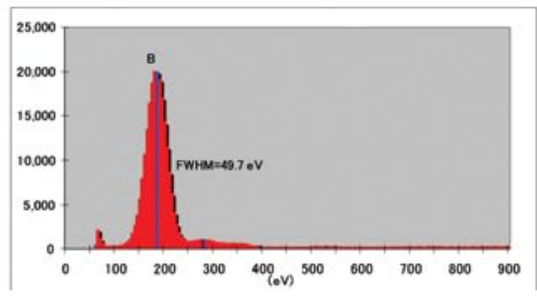

Boron

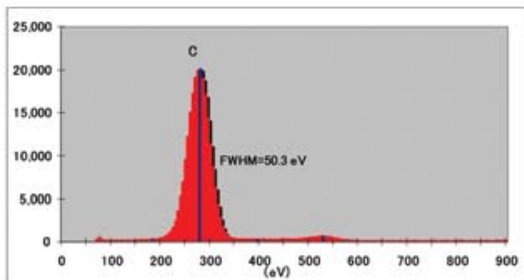

Carbon

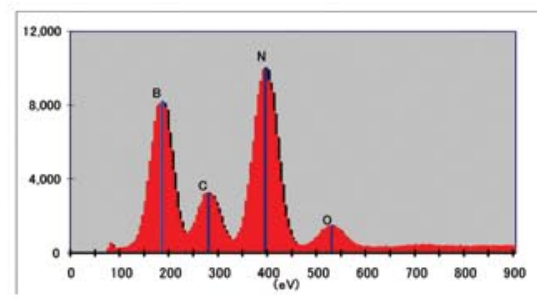

Boron Nitride

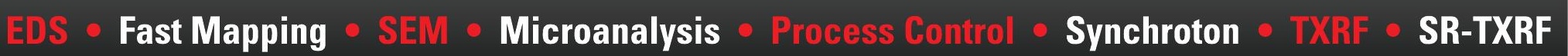

